\title{
Efecto de la sacarosa en la producción de celulosa por Gluconacetobacter xylinus en cultivo estático
}

\author{
Effect of sucrose in the production of cellulose by \\ Gluconacetobacter xylinus in static culture
}

\author{
Rubén Jaramillo L, ${ }^{1,2 *}$ Ph.D, Wladimir Tobio J, ${ }^{1,3}$ Ing, José Escamilla M, ${ }^{4}$ Ph.D.
}

\begin{abstract}
${ }^{1}$ Universidad Libre, Facultad de Ciencias de la Salud, Laboratorio de Investigación, Grupo de Investigación en Biomembranas (GIBIOM), Barranquilla, Colombia. ${ }^{2}$ Universidad de Sucre, Facultad de Educación y Ciencias, Programa de Biología, Laboratorio de Investigación en Microbiología (LIM), Grupo de Investigación en Biología de Microorganismos (GIBM), Sincelejo, Colombia. ${ }^{3}$ Universidad del Atlántico, Programa de Ingeniería Química, Facultad de Ingeniería, Barranquilla, Colombia. ${ }^{4}$ Instituto de Fisiología Celular, Universidad Nacional Autónoma de México, Ciudad Universitaria 04510, México, D.F., México. *Correspondencia: rjaramillo@unilibrebaq.edu.co
\end{abstract}

Recibido: Noviembre de 2010; Aceptado: Agosto de 2012.

\section{RESUMEN}

Objetivo. Determinar el efecto de sacarosa en la productividad de BC por Gluconacetobacter xylinus IFO 13693 en condición estática. Materiales y métodos. La síntesis de celulosa bacteriana (BC) por Gluconacetobacter xylinus se llevo a cabo en un cultivo estático discontinuo a temperatura ambiente, en presencia de sacarosa como la principal fuente de carbono a concentraciones iniciales de 0.8 a $7.6 \%(\mathrm{p} / \mathrm{v})$. Las concentraciones remanentes de BC, sacarosa, glucosa y fructosa se determinaron cada semana. Para la cinética de la hidrólisis de la sacarosa y formación de celulosa y el coeficiente de rendimiento del producto se utilizo el software Microcal Origin $6.0^{\circledR}$. Resultados. En la cuarta semana los valores de BC se encontraron entre 32.5 a $39.5 \mathrm{~g} / \mathrm{L}$ para las diferentes concentraciones de sacarosa. La cinética para la hidrólisis de sacarosa se ajusta al modelo de Michaelis-Menten, con una Vmax de $0.0002 \mathrm{~mol} \mathrm{~L}^{-1} \mathrm{~h}^{-1} \mathrm{y} \mathrm{Km}$ de $0.018 \mathrm{M}$. La producción de BC se ajusta al modelo propuesto por Marx-Figini y Pion, con un valor de la pendiente $\left(k_{c}\right)$, entre 0.0018 y $0.0024 \mathrm{~h}^{-1}$ para las diferentes concentraciones iniciales de sacarosa. Los coeficientes de rendimiento tienen valores de 0.8 a $2.4 \mathrm{~g}$ de BC producida/g de sacarosa consumida. Conclusiones. La hidrólisis de sacarosa, el consumo de glucosa y fructosa se refleja en la síntesis de celulosa. La hidrólisis de sacarosa y la producción de BC se ajustan a los modelos de Michaelis-Menten y al propuesto por Marx-Figini y Pion, respectivamente. Finalmente, el rendimiento depende de la concentración de sacarosa.

Palabras clave: Celulosa, cinética, Gluconacetobacter xylinus, sacarosa (Fuente:CAB). 


\section{ABSTRACT}

Objective. Determine the effect of sucrose on the productivity of BC by Gluconacetobacter xylinus IFO 13693 in static condition. Materials and methods. The synthesis of bacterial cellulose (BC) by Gluconacetobacter xylinus was carried out in a discontinuous static culture at room temperature, in the presence of sucrose as the main carbon source at initial concentrations of 0.8 to $7.6 \%(\mathrm{p} / \mathrm{v})$. The residual concentrations of $\mathrm{BC}$, sucrose, glucose and fructose were measured every week. The Microcal Origin $6.0^{\circledR}$. Software used to determine the kinetics of hydrolysis of sucrose and formation of cellulose and the coefficient of performance of the product Results. In the fourth week the BC values were between 32.5 to $39.5 \mathrm{~g} / \mathrm{L}$ for the different concentrations of sucrose. The kinetics for the hydrolysis of sucrose fits the Michaelis-Menten model, with a Vmax of $0.0002 \mathrm{~mol} \mathrm{~L}^{-1} \mathrm{~h}^{-1}$ and Km of $0.018 \mathrm{M}$. The production of $\mathrm{BC}$ follows the model proposed by Marx-Figini and Pion, with a value of the slope $\left(k_{c}\right)$ between 0.0018 and $0.0024 \mathrm{~h}^{-1}$ for different initial concentrations of sucrose. The yield coefficients have values of 0.8 to $2.4 \mathrm{~g}$ of BC produced / $\mathrm{g}$ of sucrose consumed. Conclusions. The hydrolysis of sucrose, fructose consumption and glucose is reflected in cellulose synthesis. The hydrolysis of sucrose and production of BC fit the Michaelis-Menten model and the model proposed by Marx-Figini and Pion, respectively. Finally, the performance depends on the concentration of sucrose.

Key words: Cellulose, Gluconacetobacter xylinus, kinetics, sucrose (Source:CAB).

\section{INTRODUCCIÓN}

Diferentes sistemas microbianos tienen la capacidad de sintetizar exopolisacáridos de alta pureza y estructura regular única, y ésta capacidad en los procarióticos es desarrollada en forma especial por bacterias Gram-negativas. Algunas cepas de los géneros de Achromobacter, Agrobacterium, Gluconacetobacter, Rhizobium y Sarcina, representan una alternativa potencial a la celulosa de origen vegetal; pero, la producción de celulosa bacteriana (BC) ha sido ampliamente estudiada desde los aspectos bioquímicos y genéticos (1-3) en la bacteria Gram-negativa aeróbica Gluconacetobacter xylinus (anteriormente Acetobacter xylinum). La BC tiene significativas ventajas sobre la celulosa vegetal debido a que se caracteriza por ser químicamente pura, libre de lignina y hemicelulosa, como también por sus fibras ultra finas, alta fuerza mecánica (fuerza tensil), biodegradabilidad, capacidad para absorber agua y altamente cristalina $(1,4,5)$. Las principales características de la BC la consideran de mucho interés debido a sus múltiples aplicaciones, como las alimenticias (fibra dietética, espesante, Té de manchú, nata de coco), farmacéuticas, médicas (sustituto temporal de la piel), ambientales (derrames de aceite), acústicas (alta velocidad sónica), producción de papeles y sus derivados, entre otros $(1,4)$.

La producción de BC por Gluconacetobacter xylinus depende de la composición del medio de cultivo, pH y tensión de oxígeno. Se ha reportado el efecto de diferentes fuentes de carbono y nitrógeno como glucosa, fructosa, sacarosa, manosa, glicerol, melaza, lactato, citrato, etanol, licor de maíz (CSL), soya, extracto de levadura, peptona, hidrolizado de caseína, amonio, agua de coco en un rango de $\mathrm{pH} 4.5$ a 5.5 sobre la síntesis de la celulosa (6-8). La producción de $\mathrm{BC}$ se ha realizado en condiciones estáticas y agitados en forma continua o discontinua en diferentes biorreactores con agitación constante y/u oxígeno (7,9-11); además, se destaca la utilización de distintas configuraciones de los biorreactores, como el reactor air lift (12) con un flujo de oxigeno que permite la agitación del medio logrando un menor consumo de potencia y un coeficiente de transferencia de oxígeno alto, y el reactor con discos paralelos, perpendiculares a un eje horizontal con rotación, a los cuales se adhiere la película de celulosa (13); asimismo, se han presentado diferentes arreglos de agitadores como el de turbina, cordón helicoidal, tornillo con tubo de succión, compuerta con turbina y Maxblend $(4,14)$. Los datos publicados permiten concluir que no se ha generado un proceso de producción a bajo costo, donde se formule un medio de cultivo económico con un modelo de biorreactor eficiente y aeración adecuada en donde se pueda obtener una productividad muy alta de $\mathrm{BC}$ que se pueda escalar con fines industriales.

Gluconacetobacter xylinus en condiciones estáticas de cultivos $(9,11,15,16)$ produce 
celulosa en forma de una película superficial en la interfase aire-líquido a temperatura ambiente, visiblemente plana y puede ser procesada posteriormente con un tratamiento alcalino; mientras, que en condiciones de agitación $(5,12)$ es producida como suspensión fibrosa con una alta viscosidad que implica a su vez una gran fuerza de agitación si se desea mantener un alto coeficiente de transferencia de oxígeno. Se han investigado la capacidad de transferencia de oxígeno $\left(\mathrm{K}_{\mathrm{L}} \mathrm{a}\right)$, tiempo de mezclado, balance de masa de carbono, velocidad de producción de $B C(\mathrm{~g} / \mathrm{L} / \mathrm{h})$, rendimiento $(\%)$ y otros parámetros en condiciones estática y agitación con oxígeno $\mathrm{y} / \mathrm{o}$ aeración en reactores con diferentes características $(4,12,14,17,18)$. Se ha publicado un trabajo con un estudio cinético sistemático para entender la producción de BC por Gluconacetobacter xylinus en un cultivo agitado y discontínuo (19). A pesar del interés en la producción de BC, los estudios de cinética de la producción de $\mathrm{BC}$ en cultivos estáticos son escasos, el cual es una necesidad que surge en la etapa de diseño de los sistemas de producción de celulosa a escala industrial, con el objetivo de entender y optimizar el proceso de producción de $\mathrm{BC}$.

En el presente estudio diferentes concentraciones iniciales de sacarosa como fuente de carbono, fueron adicionadas al medio de cultivo al inicio de los experimentos para investigar la productividad de BC por Gluconacetobacter xylinus IFO 13693 en condición limitada de oxígeno.

\section{MATERIALES Y MÉTODOS}

Microorganismo. Se usó la cepa de Gluconacetobacter xylinus IFO 13693, donada por el Dr. Edgardo Escamilla del Instituto de Fisiología Celular de la Universidad Nacional Autónoma de México (UNAM).

Medios de cultivo. Para el mantenimiento de Gluconacetobacter xylinus se usó el medio de Hestrin y Schramm (20) modificado, y la bacteria se cultivó a $30^{\circ} \mathrm{C}$ en condiciones estáticas hasta la aparición de BC. La composición del medio de cultivo líquido fue la siguiente: sacarosa, pulpa de tomate, amonio, citrato y suplementado con sales de magnesio, fosfato, calcio y potasio. Diferentes valores de concentración inicial de sacarosa fueron utilizados en porcentaje ( $\% \mathrm{p} / \mathrm{v})$ : $0.8,1.7,2.8,4.9,5.9$ y 7.6. Finalmente, el pH del medio se ajustó a 5.5 con $\mathrm{NaOH} 1.0 \mathrm{~N} \mathrm{O} \mathrm{HCl}$ $10 \%(\mathrm{v} / \mathrm{v})$, y todos los medios de cultivo fueron esterilizados en una autoclave a $121^{\circ} \mathrm{C}$ durante $20 \mathrm{~min}$.
Condiciones de cultivo. Colonias de Gluconacetobacter xylinus fueron inoculadas en $500 \mathrm{~mL}$ de medio de cultivo en un matraz Erlenmeyer de $2 \mathrm{~L}$ y se adicionó etanol $1.0 \%$ $(\mathrm{v} / \mathrm{v})$, las cuales fueron incubadas a $30^{\circ} \mathrm{C}$ por $24 \mathrm{~h}$ en agitación a $125 \mathrm{rpm}$. Posteriormente, previo control de pureza, fue seleccionado el matraz Erlenmeyer del preinóculo con mayor turbidez y formación de pequeñas fibras de celulosa, el cual fue transferido a un volumen adecuado de medio de cultivo e incubado a $30^{\circ} \mathrm{C}$ por $24 \mathrm{~h}$ en agitación a $125 \mathrm{rpm}$. Este inóculo activado fue transferido a los 72 biorreactores cilíndricos de vidrio, de $9.5 \mathrm{~cm}$ de diámetro y $11 \mathrm{~cm}$ de altura, con un volumen final de 200 $\mathrm{mL}$ de medio en cada biorreactor, cubiertos con papel poroso a $30^{\circ} \mathrm{C}$ por $7,14,21$ y 28 días bajo condiciones estáticas. Todos los experimentos se realizaron por triplicado.

Medición de la producción de BC. Para establecer el peso de cada película de celulosa fue retirada del biorreactor a diferentes tiempos de cultivo y fue lavada con $\mathrm{NaOH}$ $0.1 \mathrm{~N}$ a $30^{\circ} \mathrm{C}$ durante $20 \mathrm{~min}$, con el objetivo de disolver las células bacterianas. Para remover otras impurezas, la BC fue lavada con agua desionizada por dos veces y se secó parcialmente con papel absorbente antes de ser medido su peso húmedo. Posteriormente, la celulosa fue secada a $60 \pm 10^{\circ} \mathrm{C}$ hasta que el peso alcanzara un valor constante (6), el cual corresponde al peso seco de la BC. La variación entre las replicas fue menor que el $9 \%$.

Medición de la fuente de carbono. Un volumen del medio remanente de cada uno de los biorreactores a los diferentes tiempos de cultivo fueron inmediatamente centrifugadas a 15000 rpm (Beckman ${ }^{\circledR}$ Centrifuge AvantiTM J-25 I, U.S.A.) por $30 \mathrm{~min}$ a $4^{\circ} \mathrm{C}$ para sedimentar los sólidos suspendidos, y $5 \mathrm{~mL}$ del sobrenadante fueron utilizados en la cuantificación inmediata de glucosa, fructosa y sacarosa o almacenados a $-70^{\circ} \mathrm{C}$. La glucosa fue determinada por el método de glucosa oxidasa / peroxidasa, para lo cual se utilizó el Kit Sera-Pak (Bayer ${ }^{\circledR}$ ). El método de Taylor (21) fue utilizado en la cuantificación de fructosa; se mezclaron $25 \mu \mathrm{L}$ de la muestra (sobrenadante), $25 \mu \mathrm{L}$ del reactivo de triptamina y $750 \mu \mathrm{L}$ de $\mathrm{HCl}$ concentrado y esta solución fue colocada en un baño de agua termorregulado a $60^{\circ} \mathrm{C}$ por $15 \mathrm{~min}$, y fue leído a temperatura ambiente contra un blanco de reactivo a $518 \mathrm{~nm}$ (Beckman Spectrophometer DU ${ }^{\circledR}$ 600, U.S.A.); una curva patrón, de 0 a $12 \mu \mathrm{g}$ de fructosa fue utilizada para obtener la concentración de las muestras. En la identificación de sacarosa se utilizó el método fenol-ácido sulfúrico (22); se mezclaron $100 \mu \mathrm{L}$ de la muestra, $100 \mu \mathrm{L}$ de la 
solución de fenol, $500 \mu \mathrm{L}$ de $\mathrm{H}_{2} \mathrm{SO}_{4}$ concentrado y se incubó a $25^{\circ} \mathrm{C}$ por $20 \mathrm{~min}$, posteriormente fue leída la densidad óptica a $490 \mathrm{~nm}$ contra un blanco reactivo; la concentración de la muestra fue determinada a partir de una curva patrón de 0 a 20 ug para sacarosa; además, es importante mencionar que a los valores obtenidos de las muestras con diferentes concentraciones de sacarosa se restó el valor obtenido del medio de cultivo con pulpa de tomate sin sacarosa. Las mediciones de sacarosa, glucosa y fructosa se realizaron por triplicado para cada uno de las muestras.

Hidrólisis de sacarosa. Para la cinética de la hidrólisis de sacarosa se utilizó el modelo de Michaelis-Menten, que relaciona la velocidad inicial de una reacción catalizada por una enzima, la concentración del sustrato y ciertas características de la enzima, como lo son la constante de saturación y la velocidad máxima de reacción (23). La velocidad de consumo de sustrato se representa por el cambio en la concentración de sacarosa con respecto al tiempo, $d S / d t$, y se obtiene de los datos experimentales por medio de una regresión polinómica de cuarto orden, mediante el software Microcal Origin $6.0^{\circledR}$, y su respectiva derivada. Para obtener la constante de Michaelis-Menten $\left(K_{m}\right)$ y velocidad máxima $\left(\mathrm{V}_{\text {máx }}\right)$ de hidrólisis de sacarosa, se integró la ecuación del modelo de Michaelis-Menten:

$v=-\frac{d S}{d t}=\frac{V_{\text {máx }} S}{K_{m}+S} \quad$ (1), la cual se reordena

quedando

$\frac{K_{m}+S}{S} d S=-V_{\text {máx }} d t \equiv \frac{K_{m}}{S} d S+d S=-V_{\text {máx }} d t$

Integrando con la condición limite $\mathrm{S}=\mathrm{S}_{0}$ cuando $t=0$, se obtiene:

$K_{m} \ln \left(\frac{S}{S_{0}}\right)+\left(S-S_{0}\right)=-V_{\text {máx }} t$ (3), la cual se reordena quedando

$-\frac{\ln \left(\frac{S}{S_{0}}\right)}{\left(S_{0}-S\right)}=-\frac{1}{K_{m}}+\frac{V_{\text {máx } t}}{K_{m}\left(S_{0}-S\right)}$, (4) en donde $\frac{\ln \left(\frac{s}{S_{0}}\right)}{\left(S_{0}-S\right)}$ es una función lineal de $\overline{\left(S_{0}-S\right)}$ y los valores $K_{m}$ y $V_{\text {máx }}$ se determinan para diferentes concentraciones de sacarosa $(S)$ en el tiempo $(t)$.

Formación de producto. La cinética de formación de celulosa descrita en este proceso, se ajusta al modelo cinético propuesto por Marx-Figini y Pion para cultivos estáticos y agitados (24). Este modelo se representa con la expresión para la formación de producto como sigue:

$\frac{d P}{d t}=k_{c} P$

(5), la cual puede ser integrada para obtener $P=P_{0} e^{K_{c} t}(6)$.

Donde $k_{c}$ representa la velocidad específica de formación de producto; $P$, la concentración del producto; $d P / d t$, la velocidad de formación de producto en el tiempo en el que se ha alcanzado una concentración $P$ de producto. La velocidad de formación de producto se representa por el cambio en la concentración de $\mathrm{BC}$ con respecto al tiempo, $d P / d t$, y se obtiene de los datos experimentales por medio de una regresión polinómica de cuarto orden, mediante el software Microcal Origin $6.0^{\circledR}$, y su respectiva derivada. La velocidad específica de formación de producto puede ser determinado graficando $\ln \frac{P}{P_{0}}$ con respecto a $t$. La pendiente de la línea resultante es $k_{c}$.

Coeficiente de rendimiento del producto. El coeficiente fue determinado como la relación de peso entre la BC producida a los 28 días y la sacarosa consumida por medio de la siguiente ecuación:

$Y_{P / S}=\frac{\Delta P}{-\Delta S}(7)$, donde $\Delta \mathrm{P}$, la cantidad de celulosa formada y $\Delta S$ el sustrato utilizado para la síntesis.

\section{RESULTADOS}

Producción de celulosa bacteriana. El efecto de la concentración de sacarosa en el tiempo sobre la producción de BC en condición estática es mostrado en la figura 1. Los pesos secos de las películas de celulosa se hallaron entre el $3 \%$ al $6 \%$ del peso húmedo de la $C B$. Las concentraciones iniciales de sacarosa $4.9,5.9$ y $7.6 \%(\mathrm{p} / \mathrm{v})$ indicaron que la síntesis de celulosa, mantiene una tendencia lineal durante los 28 días con una velocidad de formación similar de $0.066,0.068$ y $0.064 \mathrm{~g} / \mathrm{L} / \mathrm{h}$, respectivamente, lo que sugiere que la velocidad de formación de la BC no fue influenciada por estas concentraciones de sacarosa. La velocidad de producción de $\mathrm{BC}$, obtenida por regresión lineal a las $67 \mathrm{~h}$, para la concentración de sacarosa $7.6 \%(\mathrm{p} / \mathrm{v})$, fue $0.077 \mathrm{~g} / \mathrm{L} / \mathrm{h}$. En las concentraciones de sacarosa de $0.8,1.7$ y $2.8 \%$ $(\mathrm{p} / \mathrm{v})$, la velocidad de formación promedio de BC fue diferente durante los 28 días, $0.038,0.048$ y $0.058 \mathrm{~g} / \mathrm{L} / \mathrm{h}$, respectivamente. Esto sugiere que las tres concentraciones anteriores puedan influir sobre la velocidad de formación de BC. 
Las diferencias presentadas en la cantidad de celulosa sintetizada a distintas concentraciones iniciales de sacarosa, se interpretan como una consecuencia de la mayor presencia de la fuente de carbono y difusión del oxígeno de la atmósfera.

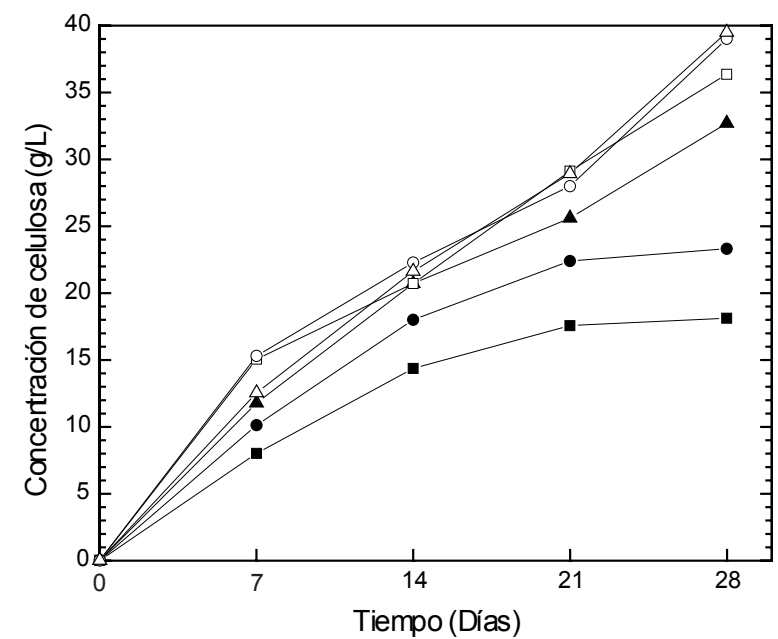

Figura 1. Producción de celulosa por Gluconacetobacter xylinus cultivada en condiciones estáticas a concentraciones iniciales de sacarosa (\% $\mathrm{p} / \mathrm{v})$ : $0.8 \square, 1.7 \bullet, 2.8 \Delta, 4.9 \square, 5.9 \circ$ y $7.6 \Delta$.

Los datos anteriores, indican que de las distintas concentraciones iniciales de sacarosa utilizadas en este medio de cultivo sencillo y económico, se destacan las correspondientes al 4.9, 5.9 y $7.6 \%(p / v)$ debido a una mayor producción de BC a los 21 y 28 días (Figura 1), con valores promedio de 28.7 y $38.3 \mathrm{~g} / \mathrm{L}$, respectivamente. Los valores de $\mathrm{pH}$ (datos no mostrados) indican una variación entre 4.5 a 5.5 durante el proceso de fermentación.

Consumo de sustrato. La sacarosa y la melaza son probablemente las fuentes de carbono más apropiadas y atractivas desde el punto de vista económico para la producción de celulosa. En este estudio se utilizó la sacarosa como sustrato (Figura 2), donde el valor de la concentración inicial de sacarosa en el medio de cultivo corresponde a la concentración después de agregar el inóculo (cero días). Las concentraciones de sacarosa $0.8,1.7$ y $2.8 \%$ $(p / v)$ son hidrolizadas en las dos primeras semanas más lentamente (Figura 2), con velocidades entre 0.23 a $1.1 \mathrm{~g} / \mathrm{L} / \mathrm{d}$ (datos obtenidos por regresión lineal); sin embargo, a concentraciones mayores de sacarosa son hidrolizadas más rápidamente, con velocidades entre 1.38 a $2.6 \mathrm{~g} / \mathrm{L} / \mathrm{d}$. Las curvas de las concentraciones iniciales de sacarosa 0.8 y $1.7 \%$ $(\mathrm{p} / \mathrm{v}$ ) en los primeros 14 días (Figura 2) indican una hidrólisis de la sacarosa aproximada de un
$70 \%$, mientras que a concentraciones mayores la hidrólisis fue de un 40 a 50\%; de los 14 a los 21 días se observa un menor hidrólisis de sacarosa; posteriormente, la sacarosa residual hasta los 28 días tiende a decrecer a cero en las concentraciones menores de sacarosa, no obstante a mayores concentraciones la sacarosa residual fue de alrededor de un 10 a $30 \%$.

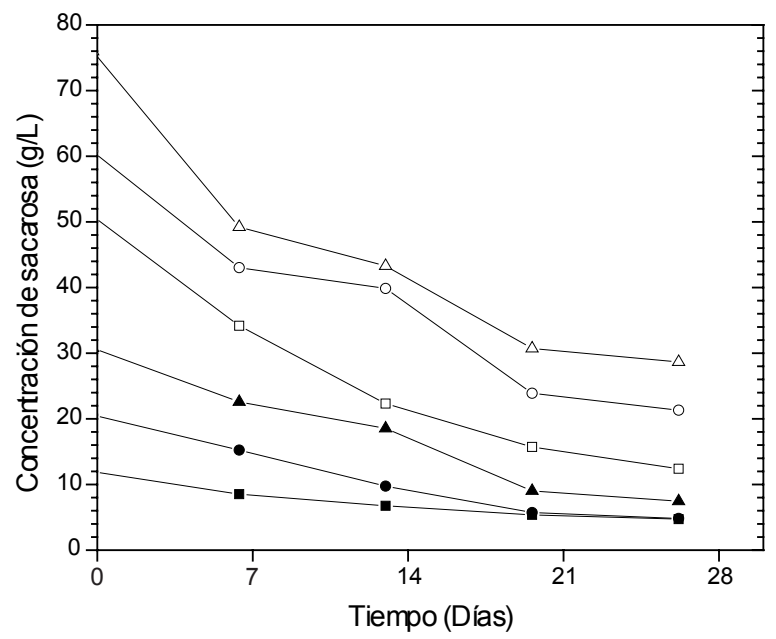

Figura 2. Cambio en la concentración de sacarosa (g/L) por Gluconacetobacter xylinus cultivada en condiciones estáticas a concentraciones iniciales de sacarosa $(\% \mathrm{p} / \mathrm{v}): 0.8(\mathbf{\square}), 1.7$ $(\bullet), 2.8(\Delta), 4.9(\square), 5.9(0)$ y $7.6(\Delta)$.

La glucosa y fructosa son utilizadas por Gluconacetobacter xylinus como fuente de carbono, energía y en la síntesis de BC. Las concentraciones de glucosa y fructosa provienen de la hidrólisis de la sacarosa inicial, del inóculo activado y del contenido de los monosacáridos en la pulpa de tomate (aproximadamente $5.6 \mathrm{~g} / \mathrm{L}$ de glucosa y $8.7 \mathrm{~g} / \mathrm{L}$ de fructosa). El comportamiento de la hidrólisis de la sacarosa (Figura 2) fue similar al consumo de glucosa (Figura 3) y fructosa (Figura 4), lo que sugiere una relación directa entre la hidrólisis de la sacarosa y el consumo de glucosa, lo cual se refleja en la síntesis de BC (Figura 1 ). La figura 3 y 4 a los siete días indica mayor consumo de glucosa con respecto a fructosa; mientras, a los 14 días el consumo de glucosa es menor que a los siete días y la diferencia con respecto a fructosa es menor. A los 21 y 28 días, la glucosa fue consumida hasta alcanzar concentraciones remanentes cercanas a cero (datos no mostrados).

En la figura 4 se observa un mayor consumo de fructosa a los 14 días que a los 7 días en las tres primeras concentraciones de sacarosa; sin embargo, a concentraciones mayores de sacarosa se observa una disminución aproximada 
entre el $16 \%$ y $32 \%$ del consumo de fructosa a los 14 días con respecto a los 7 días; asimismo, la utilización de la fructosa disminuye, debido probablemente al efecto inhibitorio de la glucosa sobre la actividad de la fructoquinasa (25). El consumo de fructosa a los 21 días es menor que a los 14 días a concentraciones de sacarosa 0.8 y $4.9 \%$ ( $\mathrm{p} / \mathrm{v}$ ) en aproximadamente un $8 \%$ y $13 \%$, respectivamente; además el consumo de fructosa a los 28 días es menor que a los 21 días, a excepción de la concentración de sacarosa $4.9 \%(p / v)$. A los 28 días, los niveles residuales de fructosa (datos no mostrados) superior a $10 \mathrm{~g} / \mathrm{L}$ de se encuentran a concentraciones mayores de sacarosa $4.8 \%(p / v)$. En resumen, los datos del consumo de glucosa y fructosa muestran la hidrólisis de la sacarosa, necesaria para la síntesis de celulosa.

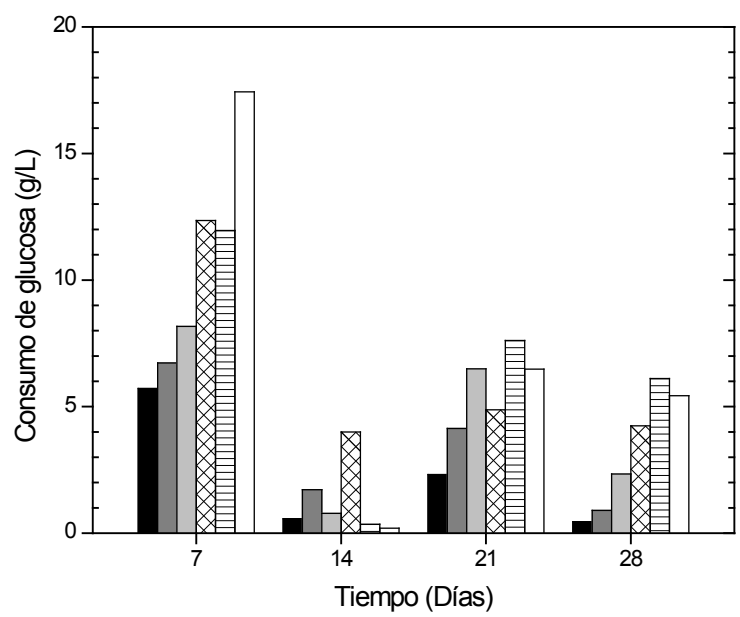

Figura 3. Consumo de glucosa $(\mathrm{g} / \mathrm{L})$ a concentraciones iniciales de sacarosa $(\% \mathrm{p} / \mathrm{v})$ : 0.8 . $1.7 \square ; 2.8 \square ; 4.9$ 図; 5.9 茞 y $7.6 \square$.

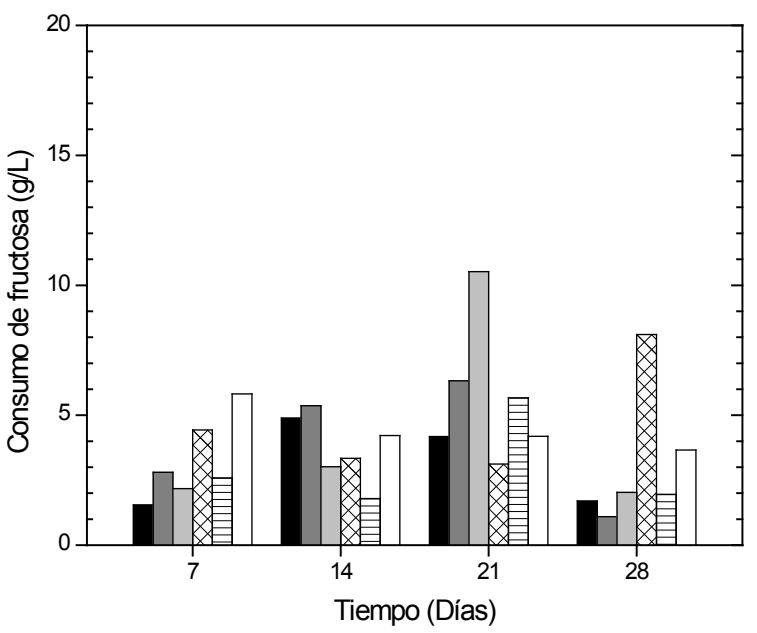

Figura 4. Consumo de fructosa a diferentes concentraciones iniciales de sacarosa (\% $\mathrm{p} / \mathrm{v}): 0.8 \square ; 1.7 \square ; 2.8 \square ; 4.9$ 网; 5.9 西 y $7.6 \square$.
Hidrólisis de la sacarosa. El modelo de Michaelis-Menten se utiliza para representar la hidrólisis de sacarosa (23). Una representación de los datos se muestra en la figura 5 a la que se le aplicó una regresión lineal para obtener la siguiente ecuación:

$\frac{\ln \frac{S}{S_{0}}}{\left(S_{0}-S\right)}=-0.15991+0.27218 \frac{t}{\left(S-S_{0}\right)}$

en donde el intercepto con la ordenada, $-\frac{1}{K_{m}}$, permite hallar la constante de Michaelis-Menten, $0.018 \mathrm{M}$; además, con la pendiente, $\frac{V_{\text {máx }}}{K_{m}}$, la velocidad máxima de hidrólisis de sacarosa fue $0.0002 \mathrm{~mol} / \mathrm{L} / \mathrm{h}$. La dispersión de los datos mostró un $R^{2}$ de 0.99 , lo que indicó que el modelo es adecuado para la cinética encontrada. Los valores de $K_{m}$ y $V_{\text {máx }}$ para la hidrólisis de sacarosa son escasos en este sistema de producción de celulosa.

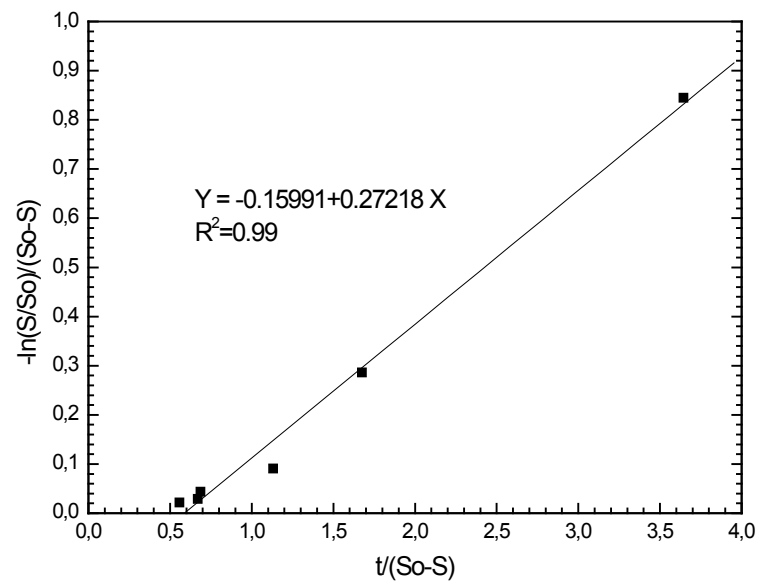

Figura 5. Regresión lineal de los datos obtenidos por la ecuación integrada de MichaelisMenten.

Formación de celulosa. Marx-Figini y Pion (24) realizaron experimentos y obtuvieron que la velocidad de formación de $B C$ y de crecimiento microbiano fueron iguales $y$ obedecen una cinética de primer orden en cultivos estáticos y agitados. Este modelo propuesto para la formación de producto se utilizó para representar la formación de BC. Los datos experimentales fueron ajustados a la ecuación, $\ln \frac{P}{P_{0}}=k_{c} t$, de donde se graficó $\ln \frac{P}{P_{0}}$  regresión lineal con una dispersión $\mathrm{R}^{2}$ de 0.99 lo que indicó la validez del modelo. La pendiente $\left(k_{c}\right)$, la cual se mantienen constante durante el proceso, se encuentra entre 0.0018 y $0.0024 / \mathrm{h}$ para las diferentes concentraciones iniciales de sacarosa, de donde se sugiere que no hay efecto 
relevante de estas concentraciones sobre la velocidad especifica de formación de producto; de lo anterior se obtiene la siguiente ecuación propuesta por el modelo de Marx-Figini y Pion:

$$
P=P_{0} e^{(0.002 t)}
$$

Rendimiento del producto. Se observa que para las mayores concentraciones iniciales de sacarosa, $4.9,5.9$ y $7.6 \%(\mathrm{p} / \mathrm{v})$, se obtiene una mayor producción de celulosa (Figura 1) con un mayor consumo de sacarosa (Figura 2) y un coeficiente de rendimiento entre 0.8 y $0.9 \mathrm{~g}$ de $\mathrm{BC}$ producida/g de sacarosa consumida (Figura $6)$, valores que indicaron un menor rendimiento en comparación a las concentraciones de 0.8 , 1.7 y $2.8 \%(p / v)$ de sacarosa, en donde se observaron rendimientos de $2.4,1.4$ y $1.3 \mathrm{~g}$ de $\mathrm{BC}$ producida/g de sacarosa consumida (Figura 6), respectivamente; por consiguiente, los últimos datos sugieren un mayor rendimiento con respecto a concentraciones menores de sacarosa $2.9 \%(p / v)$.

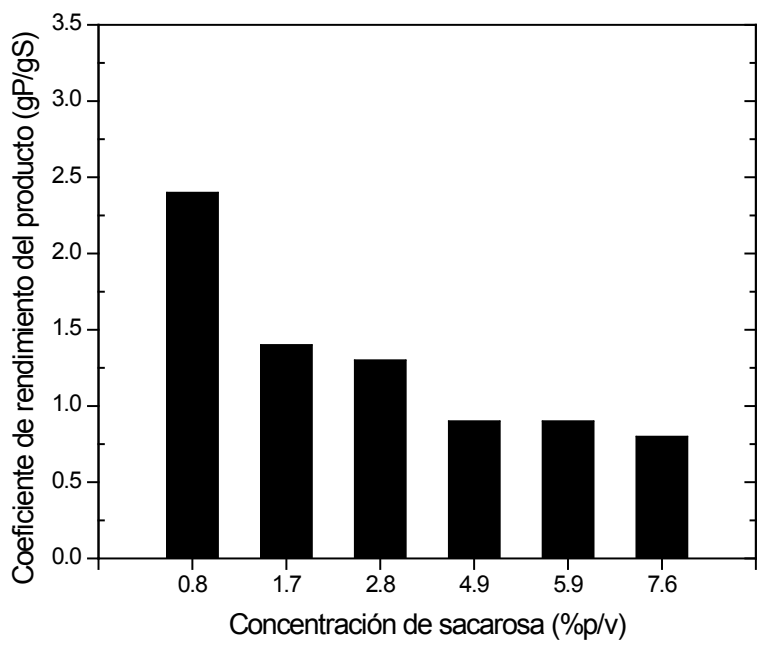

Figura 6. Efecto de las concentraciones iniciales de sacarosa en el rendimiento del producto.

\section{DISCUSIÓN}

En este estudio, la producción de películas superficiales de celulosa por Gluconacetobacter xylinus fue realizada en un medio de cultivo sencillo y económico en condición estática a temperatura ambiente, en presencia de diferentes concentraciones iniciales de sacarosa como fuente de carbono principal y pulpa de tomate. Los resultados indicaron una mayor producción de $\mathrm{BC}$ en el rango de 28 a $38 \mathrm{~g} / \mathrm{L}$ después de los 20 días a concentraciones de sacarosa 4.9 a $7.6 \%(\mathrm{p} / \mathrm{v})$, con un $\mathrm{pH}$ entre
4.5 a 5.5, rango óptimo para la producción de $B C(7,8)$. La síntesis de celulosa a estas concentraciones de sacarosa, mantiene una tendencia lineal durante los 28 días con una velocidad de formación promedio de 0.066 $\mathrm{g} / \mathrm{L} / \mathrm{h}$; sin embargo, a concentraciones de sacarosa $0.8,1.7$ y $2.8 \%(\mathrm{p} / \mathrm{v})$, la velocidad de formación promedio de BC fue diferente durante los 28 días, con valores de 0.038, 0.048 y $0.058 \mathrm{~g} / \mathrm{L} / \mathrm{h}$, respectivamente. La velocidad de producción de $\mathrm{CB}$ obtenida por regresión lineal a las 67 horas para sacarosa $7.6 \%(p / v)$ fue mayor a los datos reportados por Chao et al (10) en un reactor Airlift con suministro de aire y de Bae y Shoda (8) en un reactor convencional con melaza no tratada, 0.059 y $0.042 \mathrm{~g} / \mathrm{L} / \mathrm{h}$, respectivamente; sin embargo, la velocidad de producción de $\mathrm{BC}$ en presencia de melaza sujeta al tratamiento con ácido sulfúrico $4 \mathrm{~N}$ a $120^{\circ} \mathrm{C}$ fue de $0.074 \mathrm{~g} / \mathrm{L} / \mathrm{h}$ (8), fue muy semejante a la obtenida en este trabajo; sin embargo, se han reportado valores superiores en cultivos por lote y continuos en diferentes reactores y condiciones de cultivo $(4,14)$.

En respuesta a una eficiente hidrólisis de la sacarosa por Gluconacetobacter xylinus, el proceso de producción de la $B C$ se vio favorecido en la interfase aire/película de celulosa (17), donde la difusión del oxígeno de la fase gaseosa tiene un efecto mayor $(11,15)$; sin embargo, parece ser que en la última semana la sacarosa se convierte en un factor limitante en las concentraciones menores de sacarosa 0.8 y $1.7 \%(p / v)$, y esto puede explicar la disminución en la síntesis de celulosa (Figura 1 ), pero a concentraciones mayores de sacarosa la síntesis de celulosa es mayor. Las concentraciones de glucosa y fructosa, provienen de la hidrólisis de la sacarosa inicial, del inóculo activado y del contenido de los monosacáridos en la pulpa de tomate.

La respuesta diferencial en el consumo de glucosa y fructosa (Figura 3 y 4 ) en los primeros siete días, puede ser explicada por distintos procesos metabólicos, como la utilización de la glucosa para síntesis de BC $(12,20,26)$, como sustrato endógeno de la cadena respiratoria (3), en el vía de la pentosa fosfato y ciclo de Krebs $(1,27)$, y por los mecanismos de regulación de la fructoquinasa (25). La disminución en el consumo de la glucosa a los 14 días (Figura 3) puede estar relacionada a la regulación en los mecanismos de control de la transformación de la glucosa hasta uridin difosfato-glucosa (intermediario en la biosíntesis de la celulosa) y/o de la inhibición de la glucosa-6-fosfato deshidrogenasa-NAD (27-28). Los datos indicaron un mayor consumo de glucosa 
durante los 28 días con respecto a fructosa, y la utilización de ambos sustratos se refleja en la síntesis de celulosa.

El modelo cinético de Michaelis-Menten para reacciones enzimáticas se ajustó en gran medida a la cinética encontrada para la hidrólisis de la sacarosa, con un valor de $K_{m} 0.018 \mathrm{M}$, y una $V_{\text {max }}$ de consumo de sacarosa de 0.0002 $\mathrm{mol} / \mathrm{L} / \mathrm{h}$; asimismo, la dispersión de los datos muestra un $\mathrm{R}^{2}$ de 0.99 , lo que indica el modelo es adecuado para la cinética encontrada. El modelo propuesto por Marx-Figini y Pion se ajusta a la cinética encontrada para la formación de celulosa, con un valor de la pendiente $\left(k_{c}\right)$ entre 0.0018 y $0.0024 / \mathrm{h}$ para las diferentes concentraciones iniciales de sacarosa, por consiguiente se sugiere que no hay un efecto relevante de las diferentes concentraciones iniciales de sacarosa sobre la velocidad específica de formación de producto; sin embargo, Taylor (19) utilizó el modelo propuesto en cultivos por lotes y agitados (500 rpm), con control de pH en 5.5 , obteniendo una velocidad de formación de $0.088 / h$; similar a la Marx-Figini y Pion, 0.05/h, quien utilizó agitación (200 rpm) sin control de $\mathrm{pH}$. En ambas condiciones se utilizó agitación, lo que puede explicar el mayor valor en las velocidades con respecto al presente estudio.

Los coeficientes de rendimiento tiene valores entre 1.3 a $2.4 \mathrm{~g}$ de BC producida/g de sacarosa consumida a concentraciones menores de sacarosa $2.9 \%(p / v)$; sin embargo, estos valores disminuyen entre 0.8 y $0.9 \mathrm{~g}$ de BC producida/g de sacarosa consumida a concentraciones mayores de sacarosa 4.8 $\%(p / v)$. El comportamiento anterior de los coeficientes de rendimiento es semejante al observado a concentraciones de 2 y $5 \%$ (p/v) de glucosa (16); de igual forma, en un medio de cultivo melaza-CSI (8), con melaza no tratada, melaza sometida a $120^{\circ} \mathrm{C}$ y melaza sujeta al tratamiento con ácido sulfúrico $4 \mathrm{~N}$ a $120^{\circ} \mathrm{C}$; asimismo, se han reportado datos diferentes del coeficiente de rendimiento dependiendo de la configuración del reactor en presencia de aire y/o aire enriquecido con oxígeno $(2,4,10,14)$, con valores entre 0.1 a $0.39 \mathrm{~g} \mathrm{BC} / \mathrm{g}$ fructosa 0 glucosa.

La hidrólisis de sacarosa, el consumo de glucosa y fructosa se refleja en la síntesis de celulosa. La hidrólisis de sacarosa y la producción de BC se ajustan a los modelos de MichaelisMenten y al propuesto por Marx-Figini y Pion, respectivamente; finalmente, los resultados obtenidos en la caracterización del proceso de síntesis de celulosa por Gluconacetobacter xylinus en este estudio, permiten avanzar en el diseño de un medio de cultivo de bajo costo y de un sistema de biorreactor que contribuya a una alta productividad de $\mathrm{BC}$ en un tiempo reducido, en perspectiva de escalar este bioproceso a nivel industrial.

\section{Agradecimientos}

Este trabajo fue financiado por el Centro de Investigaciones de la Universidad Libre (CIUL) Seccional Barranquilla, en el marco del proyecto Caracterización de la síntesis de celulosa por Acetobacter xylinum. Expresamos un aprecio profundo a Deiver M. Cortina R. y José L. Villarreal C. por la ayuda generosa en algunos métodos utilizados.

\section{REFERENCIAS}

1. Bielecki S, Krystynowicz A, Turkiewicz M, Kalinowska H. Bacterial Cellulose. In: Alexander Steinbüchel A. and Sang Ki Rhee S.K., editors. Polysaccharides and Polyamides in the Food Industry: Properties, Production, and Patents. Vol 1. Weinheim: Wiley-VCH Verlag; 2005.

2. Yasutake $Y$, Kawano S, Tajima K, Yao M, Satoh Y, Munekata M, Tanaka I. Structural characterization of the Acetobacter xylinum endo-beta-1,4-glucanase CMCax required for cellulose biosynthesis. Proteins 2006; 64(4): 1069-1077.
3. Chavez-Pacheco JL, Martinez-Yee S, Contreras ML, Gomez-Manzo S, MembrilloHernandez J, Escamilla JE. Partial bioenergetic characterization of Gluconacetobacter xylinum cells released from cellulose pellicles by a novel methodology. J Appl Microbiol 2005; 99(5):1130-1140.

4. Chawla PR, Bajaj IB, Shrikant A, Survase SA, Singhal RS. Microbial Cellulose: Fermentative Production and Applications. Food Technol Biotechnol 2009; 47(2):107-124. 
5. Heo M-S, Son H-J. Development of an optimized, simple chemically defined medium for bacterial cellulose production by Acetobacter sp. A9 in shaking cultures. Biotechnol Appl Biochem 2002; 36(Pt 1):41-45.

6. Ramana KV, Tomar A, Singh L. Effect of various carbon and nitrogen sources on cellulose synthesis by Acetobacter xylinum. J Microbiol Biotechnol 2000; 16:245-248.

7. Noro N, Sungano Y, Shoja M. Utilization of the buffering capacity of corn steep liquor in bacterial cellulose production by Acetobacter xylinum. Appl Microbiol Biotechnol 2004; 64:199-205.

8. Bae SO, Shoda M. Production of bacterial cellulose by Acetobacter xylinum BPR2001 using molasses medium in a jar fermentor. Appl Microbiol Biotechnol 2005; 67(1):45-51.

9. Krystynowicz A, Czaja W, Wiktorowska-J A, Gonçalves-MM, Turkiewicz M, Bielecki S. Factors affecting the yield and properties of bacterial cellulose. J Ind Microbiol Biotechnol 2002; 29:189-195.

10. Chao Y, Sugano Y, Shoda M. Bacterial cellulose production under oxygen-enriched air at different fructose concentrations in a 50-liter, internal-loop airlift reactor. Appl Microbiol Biotechnol 2001; 55:673-679.

11. Moon S-H, Park J-M, Chun H-Y, Kim S-J. Comparisons of physical properties of bacterial celluloses produced in different culture conditions using saccharified food wastes. Biotechnol Bioproc Eng 2006; $11: 21-31$.

12. Cheng HP, Wang PM, Chen JW, Wu WT. Cultivation of Acetobacter xylinum for bacterial cellulose production in a modified airlift reactor. Biotechnol Appl Biochem 2002; 35:125-132.

13. Serafica G, Mormino R, Bungay $H$. Inclusion of solid particles in bacterial cellulose. Appl Microbiol Biotechnol 2002; 58:756-760.

14. Shoda M, Sugano Y. Recent advances in bacterial cellulose production. Biotechnol Bioprocess Eng 2005; 10(1):1-8.
15. Phunsri A, Tammarate $P$, Krusong $W$, Tantratian S. The liquid/air interface area and depth of liquid medium suitable for cellulose production from Acetobacter TISTR 975. J Sci Res Chula Univ 2003; 28(1):35-43.

16. Caicedo LA, De França FP, Lopez L. Factores para el escalado del proceso de producción de celulosa por fermentación estática. Rev Col Quím 2001; 30(2):155-162.

17. Verschuren $P$, Cardona $T$, Nout $M$, De Gooijer K, Van Den Heuvel J. Location and limitation of cellulose production by Acetobacter xylinum established from oxygen profiles. J Biosci Bioeng 2000; 89(5):414-419.

18. Jung JY, Khan T, Park JK, Joong K, Chang HN. Production of bacterial cellulose by Gluconacetobacter hansenii using a novel bioreactor equipped with a spin filter. Korean J Chem Eng 2007; 24(2):265-271.

19. Taylor MA. A kinetic study of bacterial cellulose production by a bath process [Thesis Ms]. Ontario, Canada: University of Western Ontario, Faculty of Engineering Science, Department of Chemical and Biochemical Engineering; 1999.

20. Pourramezan GZ, Roayaei AM, Qezelbash QR. Optimization of culture conditions for bacterial cellulose production by Acetobacter sp. 4B-2. Biotechnology 2009; 8(1): 150-154.

21. Taylor KACC. A Colorimetric Fructose Assay. Appl Biochem Biotechnol 1995; 53(3):215-227.

22. Moonmangmee S, Kawabata K, Tanaka S, Toyama H, Adachi O, Matsushita K. A novel polysaccharide involved in the pellicle formation of Acetobacter aceti. J Biosci Bioeng 2002; 93(2):192-200.

23. Missen RW, Mims CA, Saville BA. Introduction to Chemical Reaction Engineering and Kinetics. New York: John Wiley \& Sons, Inc; 1999.

24. Marx-Figini M, Pion BG. Kinetic Investigations on Biosynthesis of Cellulose by Acetobacter xylinum. Biochim Biophys Acta 1974; 338:382-393. 
25. Ross $P$, Mayer R, Benziman M. Biochemistry of cellulose synthesis in Acetobacter xylinum. In: Haigler $\mathrm{CH}$, Weiner $\mathrm{PJ}$, editors. Biosynthesis and Biodegradation of Cellulose. New York: Marcel Dekker, Inc.; 1991.

26. Hornung $M$, Ludwig $M$, Gerrard AM, Schmauder H-P. Optimizing the Production of Bacterial Cellulose in Surface Culture: Evaluation of Substrate Mass Transfer Influences on the Bioreaction (Part 1). Eng Life Sci 2006; 6(6):537-545.
27. Benziman M, Rivetz B. Factors affecting hexose phosphorilation in Acetobacter xylinum. J Bacteriol 1972; 111(2):325-333.

28. Mazover A, Benziman $M$. The glucose dehydrogenase activity of the NAD-linked glucose 6-phosphate dehydrogenase from Acetobacter xylinum. FEBS Lett 1973; 36(2):203-206. 